\title{
Population Dynamics in Bangladesh: Data sources, current facts and past trends
}

\author{
K. S. Farid ${ }^{1}$, J. U. Ahmed ${ }^{2}$, P. K. Sarma ${ }^{3}$ and S. Begum ${ }^{4}$ \\ ${ }^{1}$ Department of Rural Sociology, Bangladesh Agricultural University, Mymensingh-2202, Bangaldesh, ${ }^{2}$ Department of \\ Agricultural Economics, Sylhet Agricultural University, Sylhet, ${ }^{3}$ Bangladesh Agricultural University Research system, \\ Bangladesh Agricultural University, Mymensingh-2202 and ${ }^{4}$ Department of Botany, M.C.College, Sylhet, Bangladesh
}

\begin{abstract}
An understanding of past, from which we learn, and present, through which we observe, population dynamics is necessary for development planning for a country. This paper studies this present facts of and past trends in population dynamics paying particular attention to the major demographic variables of population, fertility, mortality, and migration profiles in the last two decades with an assessment of various demographic data sources in Bangladesh. In doing so various literatures were reviewed and secondary data were generated mostly from international sources, like database of the United Nations, Population Reference Bureau, US Census Bureau etc., and partly from national sources, like population census, Bangladesh demographic and health survey etc., which are the major sources of demographic data for Bangladesh. The study observes that the demographic indicators of Bangladesh have shown considerable development during the last two decades. Though the population increased in size but growth showed a declining trend. The total fertility rate declined from 3.96 children per woman during 19901995 to 2.36 during 2005-2010, and infant mortality and under-five mortality rates almost halved during the same period. Life expectancy at birth recently reached to 69 years from 56 years in 1990. Moreover, international outmigration showed an increasing trend with a very low rate for female.
\end{abstract}

Keywords: Demographic data, Population, Fertility, Mortality, Migration

\section{Introduction}

Today, about 6.87 billion people live on earth (United Nations, 2010). The worlds population has experienced continuous growth since 1400. The highest rate of growth (about $1.8 \%$ per year) were seen briefly during the 1950s, and then for a long period during the 1960s and 1970s. The growth rate of population peaked at $2.2 \%$ in 1963 , and declined to $1.1 \%$ by 2009 . Current projections show a continued increase in the number of population with a steady decline in the growth rate. The world population expected to reach 9 billion by 2050. Most of the additional 2.3 billion people expected by this period will be concentrated in developing countries. The population of the developing countries is projected to rise from 5.6 billion in 2009 to 7.9 billion in 2050 (United Nations, 2009). Again, Asia is simply earth population giant. Numerically, Asia will likely add about 1.5 billion population by 2050 (Haub, 2002). Among various countries of Asia, Bangladesh is a country with huge population. It is the seventh most populous countries in the world and population is the main problem in Bangladesh which is responsible for creating many other socio-economic problems (National Institute of Population Research and Training (NIPORT), Mitra and Associates, and Macro International, 2009). It is again most densely populated countries in the world excluding small island nations and city states like Singapore and Hong Kong. The population of Bangladesh, according to UNFPA, is about 164.4 million with a density of about 1100 people per square kilometre with a growth rate of 1.4 (The Daily Star, 2010). During the second half of the last century there was rapid population growth. As a result, the number of population trippled during that period. Though population growth rate is decreaing slowly the high percentage of young population will in turn generate huge population increase in future. Projections indicate that total number of population in Bangladesh will be 222 million by 2050, the dynamics of which need to be examined (United Nations, 2010).

Population dynamics and more particularly demographic changes are intertwined with almost all critical questions human beings are facing today. In the past, changes in the size and structure of population took centuries to evolve and in some instances such changes often passed unnoticed (Haub, 2002). But now the world is undergoing constant demographic chages not only among the world's regions but also within the regions and even within countries. So, it is important to foster a greater understanding and 
knowledge about population dynamics and demographic changes. Besides, knowledge about demographic changes is necessary for political, social and economic strategy of the country in order to cope with the changing situation. For fostering demographic knowledge it is essential to analyze and evaluate demographic data which can be collected from a variety of sources. The present study is an attempt to find out the different sources of demographic data, and on the basis of of these data sources, later on to describe population dynamics of Bangladesh. Owing to this necessity, the main objective of this study is to provide a general overview of different sources of demographic data, and to describe current demographic facts and previous trends of population of Bangladesh in order to strengthen the knowledge about population dynamics so that the policy planner can make appropriate strategy to cope with the changing demographic situation of the country. To achieve the objective of the study a thorough literature review was conducted in order to gain insights into the various demographic data sources for Bangladesh. For describing the current facts and past trends in various demographic processes like population, fertility, mortality, and migraion necessary data were generated from various secondary sources for last two decades, i.e., from 1990 to 2010. In most of the cases the study used international sources, like database of United Nations, Population Reference Bureau, US Census Bureau, etc. Data were also generated from national sources like Bangladesh Demographic and Health Survey, Bangladesh Economic Review, etc. in some instances. Finally, tabular and graphical analyses of data were performed for the interpretation of the results.

\section{Materials and Methods}

\section{Demographic Data Sources in Bangladesh}

In general, demographic data can be obtained from a variety of sources, like census, vital registration system, population register, and sample surveys. Census is the "total process of collecting, compiling and publishing demographic, economic and social data pertaining at a specified time or times to all persons in a country or delomited territory"(United Nations, 1953). Vital registration is the continuous recording of "live births, deaths, feotal deaths, marriage, divorce, adoption, legitimation of birth, recognition of parenthood, annulment of marriage, or legal seperation"(United Nations, 2003). Through sample survey information is collected from a sample of individuals rather than from entire population unlike census (Weeks, 2005). The most important sample survey conducted in developing countries is the Demographic and Health Survey (DHS), which provides national representative data about various socio-economic and demographic aspects of population, health, and nutrition of women and children in developing countries(Measures DHS, 2010). Besides, population register provides a continuous records of vital events containing names, addresses, age, sex etc. of every citizen including their migration status. It also keeps records of the population who enter in a country(Prins, 2000). There are some other sources of demographic data for example, hospital data, social security data, school data, etc. which are collected through administrative exercises. Nevertheless, demographic data for Bangladesh in particular can be obtained from various national and international sources.

\section{National sources of demographic data}

Census: Census is one of the important sources of demographic data in Bangladesh which is conducted by Bangladesh Bureau of Statistics. Bangladesh has a long history of census. The first one was conducted in this territory in 1872 and then the second census was undertaken in 1881. After the independence of Bangladesh, the first census was held in 1974, and the second one was in 1981 and since then censuses have been conducted in every 10 years. The last census, which was the fourth, was undertaken in 2001 (Banglapedia, 2003). The next fifth census will be conducted in March 2011 in which digital enumeration maps and a unique geo-coding system will be used for the first time in the history of the country(Mollah, 2010). Census operations covered a wide variety of information like name of the person, relationship to head of the household, sex, age, marital status, religion, literacy status, level of education, occupation, birth place, number of children ever born, number of children alive, etc.(BBS, 2007) As censuses are conducted in every 10 years in Bangladesh like many other countries, it lacks from continuous data on births, deaths and other vital data on population. In some instances census provides poor quality data which is due to the widespread illiteracy of Bangladesh. Due to this reason the people provide wrong information and there is also a lot of non-response and age misreporting occured during census operation (Banglapedia, 2003). 
Sample surveys: The another important sources of demographic data in Bangladesh is sample survey. Various types of sample surveys are conducted in Bangladesh like Bangladesh Demographic and Health Survey (BDHS), Household Income and Expenditure Survey (HIES) among which BDHS is the most important sources for demographic data. The BDHS is conducted in every three to four years to serve as a source of population data. The first one was conducted in 1994 and the latest one, which was the fifth, was conducted in 2007. It was a national representative sample survey of 10996 women aged 15-49 and 3371 men aged 15-54 from 10400 households covering a total of 361 sample points, 227 rural and 134 urban, throughout Bangladesh. The survey is designed to obtain detailed information on basic national indicators like household population characteristics by age, sex, educational attainment and residence, fertility, fertility regulation, fertility preferences, child and maternal health, infant and child mortality, maternal mortality, nutrition of children and women, knowledge, attitudes and behaviour on HIVIAIDS, women's empowerment and demographic outcomes, domestic violence, etc. Though sample surveys provide a wide variety of demographic data they sometimes suffer from representativeness the result of which is the misleading information. Another problem is that people's memory may mislead them. For that accurate information may not be found in some instances. Besides, sampling and non-sampling errors also responsible for biased result in sample surveys (National Institute of Population Research and Training (NIPORT), Mitra and Associates, and Macro International, 2009).

Demographic surveillance system: Demographic surveillance system (DSS) was started in the 1960s for collecting a wide range of data on family planning, child nutrition, epidemiology, child and maternal health etc. by International Centre for Diarrhoeal Disease Research, Bangladesh (ICDDR,B), which has been recording births, deaths and migration since 1966. For developing and dessiminating solutions to major health and population problems ICDDR,B has undertaken a vast number of research projects. Much of these researches are based on the Matlab field studies in Matlab, a sub-district (upazila) of Chandpur district, Bangladesh (Philip et al. 2000).

Vital registration: Vital registration system is very much weak in Bangladesh. Although birth registration is started recently there is no continuous record of this event because of the underdeveloped system. It is not possible to get data on birth from any central authority. There is no system of death registration in Bangladesh. Marriage registration is kept in Union Parishads (lowest administrative unit) and there is also no central database about marriage and divorce. There is however Sample Vital Registration System (SVRS) in Bangladesh, which provides data on vital event of sample population.

There is no instance of population register system in Bangladesh. Again, Bangladesh Bank, the central bank of Bangladesh, Bangladesh Economic Review published by Bangladesh Bureau of Statistics, Bureau of Manpower Employment and Training, an institute of Ministry of Labour and Expatriate Welfare, Refugee and Migratory Movement Research Unit of the University of Dhaka provide some demographic data.

\section{International demographic data sources}

United Nations: The United Nations population and statistics division compile and dessiminate global population data including Bangladesh. The population division of the United Nations published World Population Prospects: The 2008 Revision which contains demographic data from 1950 with a projection until 2050. The database include number of population, population density, population by five-year age group and sex, sex ratio, sex ratio at birth, population growth rate, number of births and deaths, births by age group of mother, crude birth rate, crude death rate, age-specific fertility rate, total fertility rate, net reproduction rate, infant mortality rate, under-five mortality rate, life expectancy at birth, net migration, net migration rate, etc. The UN Demographic Year Book also collects, compiles and disseminates some population data in coordination with Bangladesh Bureau of Statistics. It provides information on population size, composition, births, deaths etc. on an annual basis, and fertility and mortality estimates based on five-year interval. The UN database (migration stock) also provides estimates on number of international migrants classified by sex, refugees, international migrants as percentage of the population, and female and refugees as percentage of all international migrants at mid-year population (United Nations, 2010). 
Demographic and Health surveys: Demographic and Health Surveys (DHS) are nationally representative household surveys that provide data for wide range indicators in the areas of population, health, and nutrition. DHS provides reliable demographic data for Bangladesh since 1994. The survey obtained detailed information on fertility levels, marriage, fertility preferences, awareness and use of family planning methods, breastfeeding practices, nutritional status of women and young children, childhood mortality, maternal and child health, and knowledge and attitudes regarding HIVIAIDS and other sexually transmitted infections (STIs) (Measure DHS, 2010).

Population reference bureau (PRB): PRB is a database with hundreds of variables which also includes demographics of Bangladesh including data on population size and density with projections, birth and death rate, rate of natural increase, net migration rate, infant mortality rate, total fertility rate, percentage of population aged below 15 years and above 65 years, life expectancy at birth classified by sex, median age at marriage, etc. This database consists of stock data and it made comparison with world average (PRB, 2010).

US Census bureau- International database: The international database of US Census Bureau provides estimates of population, births, deaths and migration. It provides trend on population processes and compares demographic status of Bangladesh with global average. It provides data on population size, fertility measures and indicators, mortality and migration (US Census Bureau, 2010).

\section{Results and Discussion}

\section{Current demographic facts of Bangladesh}

Population estimates about Bangladesh can be found from a variety of sources. Table 1 shows various indicators of Bangladesh population according to two sources: US Census Bureau and United Nations.

Table 1. Current demographic facts, 2010

\begin{tabular}{|c|c|c|}
\hline \multirow[t]{2}{*}{ Indicators } & \multicolumn{2}{|c|}{ Sources } \\
\hline & US Census Bureau & United Nations \\
\hline $\begin{array}{l}\text { Mid-year population '000 } \\
\text { leMa } \\
\text { Female } \\
\text { Total }\end{array}$ & $\begin{array}{c}76026 \\
80092 \\
156118\end{array}$ & $\begin{array}{c}83134 \\
81291 \\
164425\end{array}$ \\
\hline Growth rate (\%) & 1.55 & 1.42 \\
\hline Number of births '000 & 3658 & 3378 \\
\hline Crude birth rate & 23.43 & 21.6 \\
\hline Total fertility rate & 2.65 & 2.36 \\
\hline Sex ratio at birth & 1.04 & 1.03 \\
\hline Number of deaths '000 & 907 & 1078 \\
\hline Crude death rate & 5.81 & 6.6 \\
\hline $\begin{array}{l}\text { Infant mortality rate } \\
\text { Male } \\
\text { Female } \\
\text { Total }\end{array}$ & $\begin{array}{l}55.04 \\
49.94 \\
52.54\end{array}$ & $\begin{array}{l}46.4 \\
42.8 \\
44.7\end{array}$ \\
\hline Under five mortality rate & 66 & 57 \\
\hline $\begin{array}{l}\text { Life expectancy at birth } \\
\text { Male } \\
\text { Female } \\
\text { Total }\end{array}$ & $\begin{array}{l}67.64 \\
71.30 \\
69.44\end{array}$ & $\begin{array}{l}66.5 \\
69.0 \\
67.7\end{array}$ \\
\hline Net migration ‘000 & $331-$ & na \\
\hline Net migration rate & $2.12-$ & 1.00 \\
\hline Population density (no. per sq. km.) & na & 1142 \\
\hline
\end{tabular}

Source: US Census Bureau, 2010 ; United Nations, 2010 Note: na = not available 
The total number of population as of 2010 estimated by US Census Bureau is about 156,118 thousnads, whereas the United Nations estimate counts about 164,425 thousands of people with a corresponding population growth rate of 1.55 and 1.42 per year, respectively. According to US Census Bureau, the annual number of births in Bangladesh currently stands at 3658 thousand with a crude birth rate of 23.43 and total fertility rate of 2.65. Accordingly the annual number of deaths is 907 thousands with 5.81 deaths per 1,000 population. Infant mortality rate and under-five mortality rate stands at 52.54 and 66 , respectively with a slight higher infant mortality among male children than that of their female counterpart. Moreover, the life expectancy at birth currently standing at 69.44 years and again higher for female than that of male. The net migration of Bangladesh shows a negative value. Indeed, population density is highest 1142 people per square kilometre (United Nations, 2010).

Fig. 1 shows the current age and sex structure of Bangladesh population and it is clear from the figure that like any other developing countries in the world a large number of people of Bangladesh constitute in the young age group which will be responsible for continuing high rate of population growth in future. However, age composition of population does not show any significant variations according to sex.

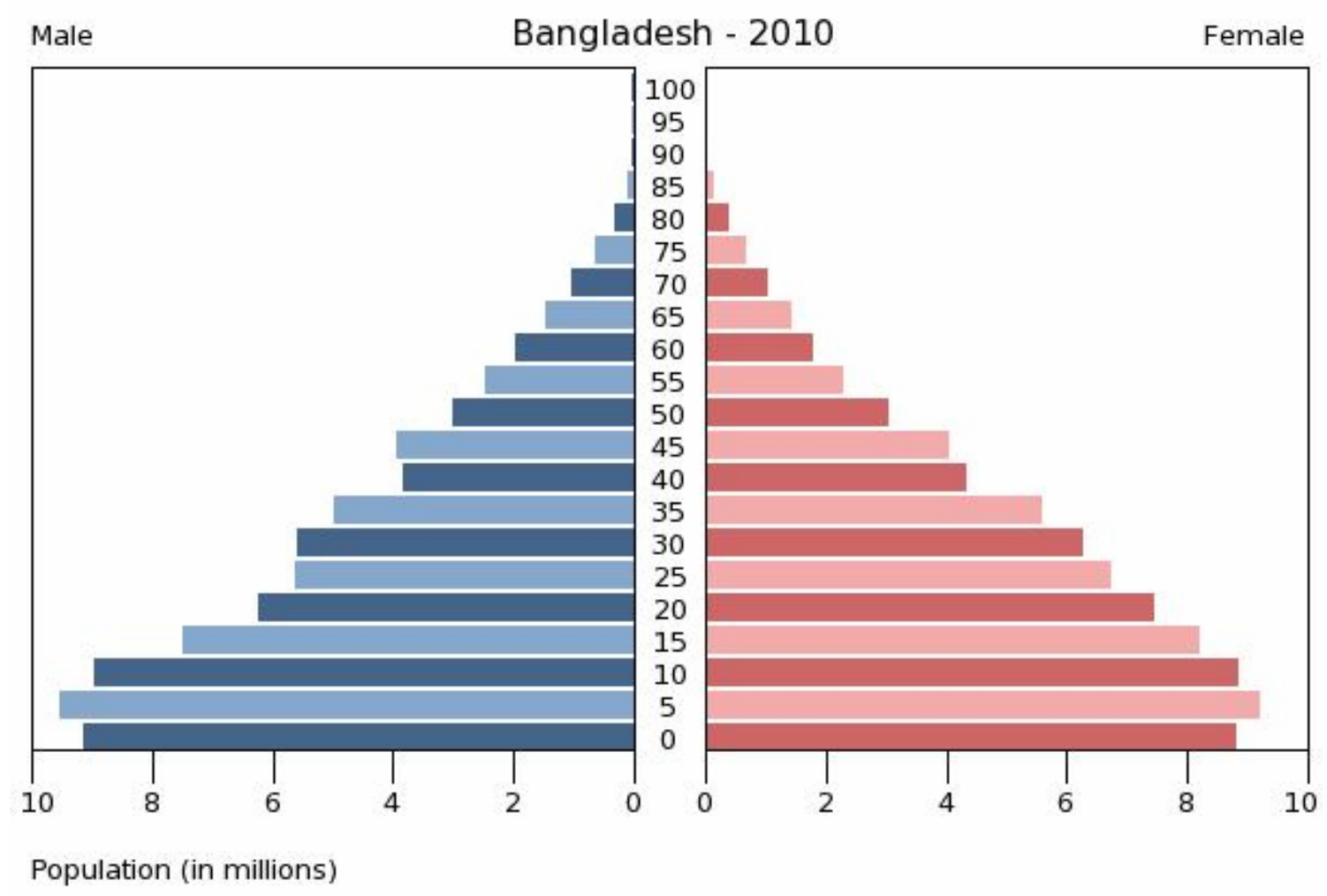

Source: United Nations, 2010

Fig. 1. Age-sex structure of population of Bangladesh as of 2010

\section{Demographic trends in Bangladesh}

Trends in population size and compositions: The number of population irrespective of structure is increasing day by day which is shown in Fig. 2. It shows the trends in the number of population by sex and it depicts an increasing trend over the years. It also shows that number of male population is bit higher than the number of female population over the whole period but both are showing positive trend. 


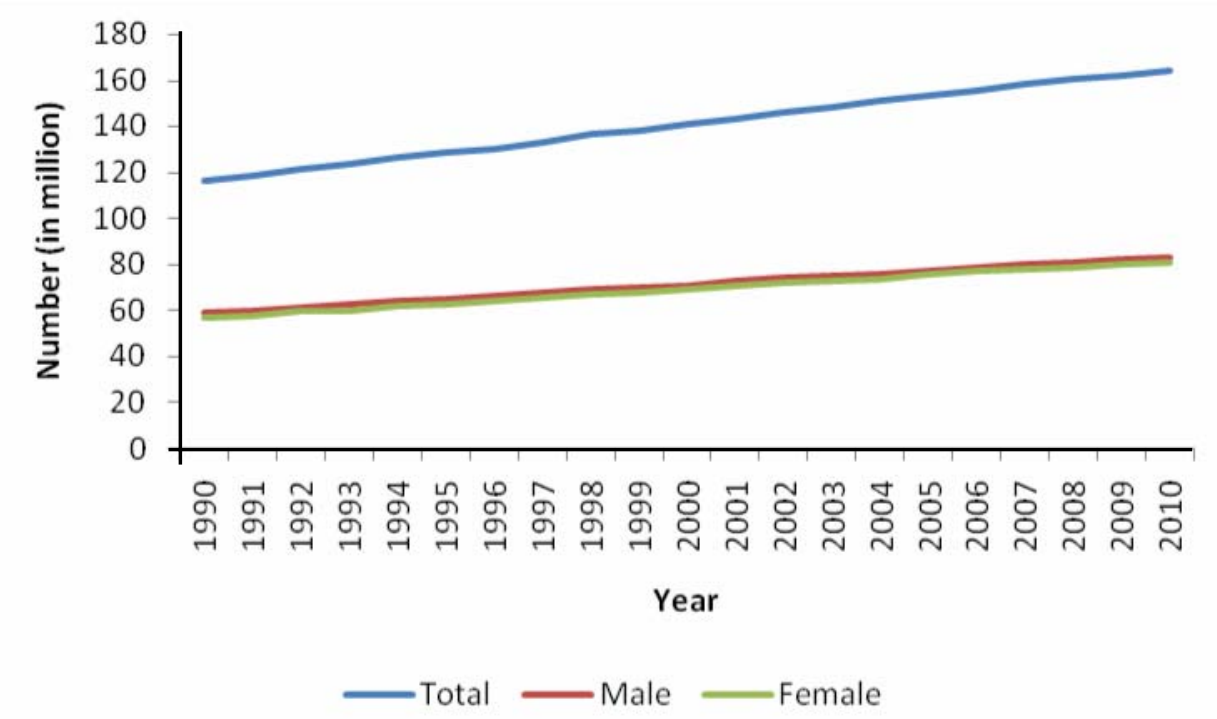

Source: United Nations, 2010

Fig. 2. Trends in population size by sex over the last two decades

Population both in number and in rate is changing in Bangladesh. Table 2 depicts that per year change in the number of population is decreasing which was 2491 thousand in the period of 1990-1995 and it is decreased to 2261 thousands during 2005-2010. Again, what is good for Bangladesh is its decreasing rate of population growth. The growth rate of population was $2.05 \%$ in $1990-1995$ and by showing a continuous decreasing trend it reached to $1.42 \%$ in $2005-2010$.

Table 2. Change in the number and growth of population

\begin{tabular}{|l|c|c|c|c|}
\hline Indicators & $1995-1990$ & $2000-1995$ & $2005-2000$ & $2010-2005$ \\
\hline Population change per year '000 & 2491 & 2536 & 2471 & 2261 \\
\hline Population growth rate (\%) & 2.05 & 1.89 & 1.68 & 1.42 \\
\hline
\end{tabular}

Source: United Nations, 2010

Trends in fertility: Estimates of fertility is of cruicial importance for a country in order to have an idea about population growth rate. Table 3 shows some basic estimates of fertility. It is evident from the table that births per year, crude birth rate, total fertility rate and net reproduction rate - all show a decreasing pattern over the period from 1990-1995 to 2005-2010 which is obviously a good indicator for Bangladesh, the country which is suffering from huge population pressure. Total fertility rate decreased to 2.36 during 2005-2010 from 3.96 during 1990-1995.

Table 3. Trends in basic estimates of fertility

\begin{tabular}{|l|l|l|l|l|}
\hline Indicators & $1995-1990$ & $2000-1995$ & $2005-2000$ & $2010-2005$ \\
\hline No. of Birth(per year in 1000) & 3938 & 3865 & 3734 & 3428 \\
\hline Crude birth rate (No. per 1000) & 32.3 & 28.8 & 25.4 & 21.6 \\
\hline Total fertility rate (no. of children per woman) & 3.96 & 3.30 & 2.80 & 2.36 \\
\hline Net reproduction rate (daughters per woman) & 1.57 & 1.38 & 1.22 & 1.06 \\
\hline
\end{tabular}

Source: United Nations, 2010 
Fig. 3 shows the age-specific fertility rate over three time period from 1995-2000 to 2005-2010. Fertility rate is higher for age group 20-24 and what is evident from the figure is that fertility rates for all age group more or less decreased over the specified time period.

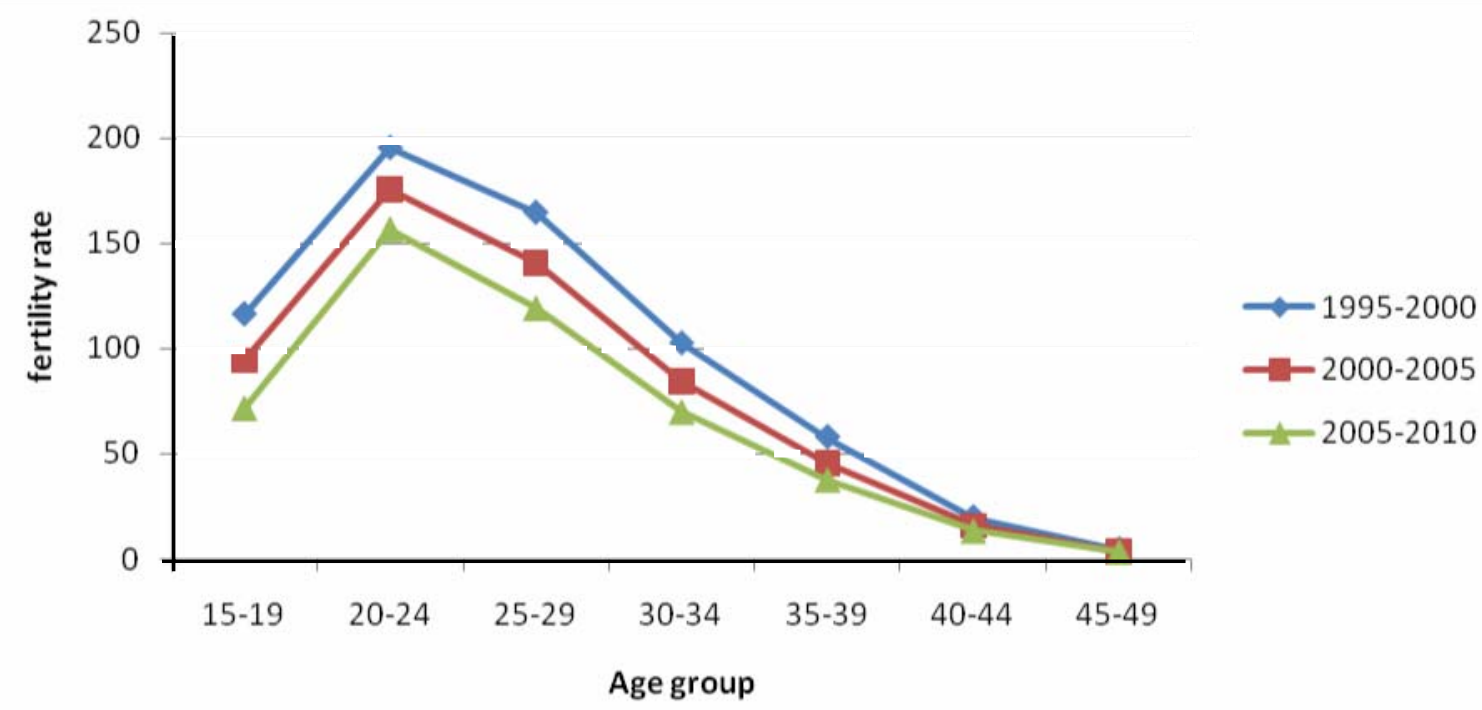

Source: United Nations, 2010

Fig. 3. Age-specific fertility rates for women of reproductive age

Trends in mortality: Number of death in Bangladesh is slightly higher for male than that of female and the death estimate both in number and in rate, and both for male and female show decreasing trend over the years (Table 4). Overall deaths per year for both sexes were 1348 during 1990-1995, which is decreased to 1053 during 2005-2010. Again, crude death rate per 1000 population also decreased to 6.6 during 2005-2010, which was 11.1 during 1990-1995.

Table 4. Estimates on death over the period of 1990-2010

\begin{tabular}{|l|c|c|c|c|}
\hline \multirow{2}{*}{ eriodP } & \multicolumn{3}{|c|}{ Deaths per year } & Crude death rate \\
& Male & Female & Both sex & \\
\hline $1995-1990$ & 709 & 639 & 1348 & 11.1 \\
\hline $2000-1995$ & 643 & 576 & 1219 & 9.1 \\
\hline $2005-2000$ & 594 & 529 & 1123 & 7.6 \\
\hline $2010-2005$ & 559 & 494 & 1053 & 6.6 \\
\hline
\end{tabular}

Source: United Nations, 2010

Table 5 depicts that child mortality rates in Bangladesh is decreasing over the year, but it is also high in compare to international average. But Bangladesh shows a tremendous success in this case as child mortality, whether infant or under-five, halved during the last two decades. Though infant mortality rate for male infant is slightly higher than that of female infant, under-five mortality rate is more or less same for both sexes. 
Table 5. Child mortality rates in Bangladesh

\begin{tabular}{|l|c|c|c|c|c|c|}
\hline \multirow{2}{*}{ Period } & \multicolumn{3}{|c|}{ y ratelnfant mortalit } & \multicolumn{3}{c|}{ five mortality rate-Under } \\
\cline { 2 - 7 } & Male & Female & Both & Male & Female & Both \\
\hline $1995-1990$ & 94.3 & 87.1 & 90.8 & na & na & na \\
\hline $2000-1995$ & 75.4 & 69.8 & 72.6 & 102 & 100 & 101 \\
\hline $2005-2000$ & 59.4 & 54.9 & 57.2 & 77 & 76 & 77 \\
\hline $2010-2005$ & 46.4 & 42.8 & 44.7 & 58 & 56 & 57 \\
\hline
\end{tabular}

Source: United Nations, 2010

During the first half of 1990s life expectancy at birth was less than 60 years for both male and female, and it was more or less same for both of the sexes. But from the later half of 1990s it crossed the boundary of 60 year and with an increasing trend it reached to 70 years in 2010. Moreover, like most of the countries in the world life expectancy in Bangladesh at present also higher for female than that of male (Fig. 4).

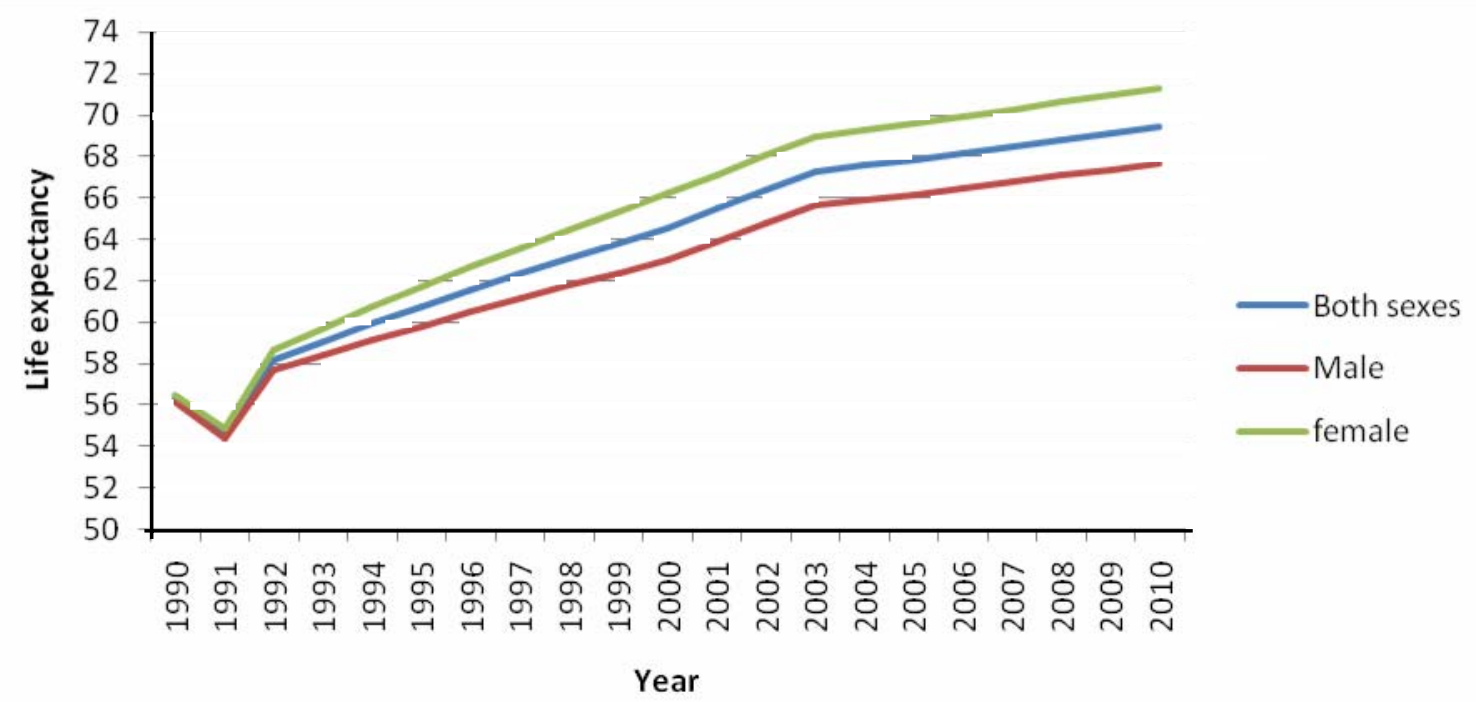

Source: United Nations, 2010

Fig. 4. Trends in life expectancy at birth classified by sex

Trends in migration: Migration statistics are very much rare in Bangladesh. Though different sources provide data on the number of international out-migration classified by destination country and by skill, data on internal migration is very scarce. Migration of Bangladesh is basically dominated by international out-migration. Since 1976 to June 2010, about 72 million Bangladeshis migrated overseas for employment (Bangladesh Bank, 2010). Bangladeshi migrant workers are predominantly men. Female migrants constitute only 2.27 per cent of the total migrants of Bangladesh (Table 6). This low rate is due to the imposition of ban in 1981 on the migration of all categories of female workers other than professional, which was later on replaced by the imposition of restrictions on the migration of women of unskilled and semi-skilled categories in 1987. A ban was again imposed in 1997 on all categories of women workers, including professional and this was changed to restriction from which professional were excluded. Since 2003, the restrictions apply only to unskilled and semi-skilled women workers under the age of 35, who are not allowed to migrate on their own. Nevertheless, this restriction increases the outflow of female migrants from Bangladesh through unofficial channels. The number of female migrants, therefore, might be 10 to 50 times more than the official figures (Siddiqui, 2005). 
Table 6. Trends in international out-migration classified by sex

\begin{tabular}{|l|c|c|c|}
\hline \multirow{2}{*}{ Period } & Total number of migrants & \multicolumn{2}{|c|}{ Women migrants } \\
\cline { 3 - 4 } & & Number & $\%$ of Total migrants \\
\hline $1991-1995$ & 953632 & 9308 & 0.98 \\
\hline $19962000-$ & 1201336 & 5046 & 0.42 \\
\hline 2001 & 188965 & 659 & 0.35 \\
\hline 2002 & 225256 & 1217 & 0.54 \\
\hline 2003 & 254190 & 2400 & 0.94 \\
\hline 2004 & 272958 & 11200 & 4.10 \\
\hline 2005 & 252702 & 13600 & 5.38 \\
\hline 2006 & 381516 & 18100 & 4.74 \\
\hline 2007 & 832609 & 18900 & 2.27 \\
\hline
\end{tabular}

Source: Bangladesh Economic Review, 2009

\section{Conclusion}

The paper provides a description of basic demographic processes of Bangladesh on the basis of the available national and international demographic data sources. To do this it firstly tries to find out the demographic data sources available for Bangladesh in both national and international level, and then to provide the current facts and trends in demographic processess of Bangladesh. The paper finds that in general demographic data on Bangladesh can mostly be obtainded from census, Bangladesh demographic and health survey, in some extent from household and expenditure survey, Bureau of manpower employment and training, Bangladesh Bank, etc. The international sources of Bangladesh demographic data include various divisions and organizations of United Nations, US Census Bureau, Demographic and Health Survey, Population Reference Bureau, etc. The paper also finds the improvement of Bangladesh in terms of various demographic processes like growth rate of population, crude birth rate, crude death rate, total fertility rate, infant mortality rate, life expectancy at birth, etc. But the number of population is increasing day by day, obviously with declining rate. However, this paper uses demographic data for Bangladesh mainly from international sources due to the unavailability of data from national sources in the format suitable for this paper. It again only describes various demographic events, and therefore, further study is needed to explain the causes of changes in demographic events in Bangladesh and also to find out the interaction between demographic changes and socio-economic changes and vice versa. Moreover, quality of demographic data in Bangladesh is questionable like many other developing countries because of the widespread illiteracy among the people of the country, who in most of the cases provide misinformation. So, its a major challenge for Bangladesh to collect quality demographic data.

\section{References}

Bangladesh Bank. 2010. The central bank of Bangladesh, Government of the People's Republic of Bangladesh, Dhaka (http://bangladesh-bank.org).

BBS. 2007. Bangladesh Bureau of Statistics, Statistics Division, Ministry of Planning, Government of the People's Republic of Bangladesh, Dhaka.

Bangladesh Economic Review. 2009. Bangladesh Economic Review, Economic advisor wing, Finance division, Government of the People's Republic of Bangladesh, Dhaka.

Banglapedia. 2003. National Encyclopedia of Bangladesh. Dhaka: Asiatic Society of Bangladesh.

Haub, C. 2002. 'World population dynamics 2002', Berlin: Institute for world population and global development.

Measure DHS. 2010. Measure DHS. Calverton: ICF Macro (http://measuredhs.com).

Mollah, M.S.A. 2010. Digital Bangladesh: Digital population census starts. available at http://gurumia.com/2010/07/20/digitalBangladesh-digital-population-census-starts accssed at 18.10.2010. 
National Institute of Population Research and Training (NIPORT), Mitra and Associates, and Macro International. 2009. Bangladesh Demographic and Health Survey 2007. Dhaka, Bangladesh and Calverton, Maryland, USA: National Institute of Population Research and Training, Mitra and Associates, and Macro International.

Phillips, J.F., MacLeod, B. and Pence, B. 2000. The Household Registration System: Computer Software for Rapid Dissemination of Demographic Surveillance Systems. Demographic Research, 2(6).

PRB. 2010. Population Reference Bureau, Washington. Available at http://www.prb.org/Datafinder/Geography/ Summary. aspx?region $=138 \&$ region_type $=2$ accessed at 19.10.2010.

Prins, C.J.M. 2000. Dutch population statistics based on population register data. Maandstatistiek van de bevolking 48 (2): pp. 9-15.

Siddiqui, T. 2005. International labor migration from Bangladesh: A descent work perspective. Working Paper No.66, Policy Integration Department, National Policy Group, International Labour Office, Geneva.

The Daily Star. 2010. 'Population 16.44 cr', The Daily Star, The daily Bangladeshi news paper, Date: 21.10.2010, 20(275): p.1, accessed at 21.10.2010 at http://www.thedailystar.net/newDesign/news-details.php?nid=159325

United Nations. 1953. 'Principles for a vital statistics system'. Statistical series M No. 19, United Nations.

United Nations. 2003. 'MBS on-line data dictionary', Monthly Bulletin of Statistics On-line, January. Available at http://unstats.un.org/unsd/mbs/ddgrid.asp at 20.10.2010.

United Nations. 2009. Population Newsletter. Department of Economic and Social Affairs, Population Division, United Nations Secretariats, June 2009, No.87.

United Nations. 2010. 'World population prospects: The 2008 revision'. Department of Economic and Social Affairs, Population Division, United Nations Secretariats.

US Census Bureau. 2010. US Census Bureau, International database, Population division, Available at http://www.census. gov/ipc/www/idb/country.php accessed at 19.10.2010.

Weeks, J.R. 2005, Population. An introduction to concepts and issues. Ninth edition. Belmont: Wadsworth Publishing. 